TEI

JOURNAL OF THE

\section{Journal of the Text Encoding Initiative}

Issue 7| November 2014

Reaching out, Opting in

\title{
Evaluating Digital Scholarship: Suggestions and Strategies for the Text Encoding Initiative
}

Sarah L. Pfannenschmidt and Tanya E. Clement

\section{(2) OpenEdition \\ Journals}

Electronic version

URL: http://journals.openedition.org/jtei/949

DOI: $10.4000 /$ jtei.949

ISSN: 2162-5603

Publisher

TEl Consortium

Electronic reference

Sarah L. Pfannenschmidt and Tanya E. Clement, «Evaluating Digital Scholarship: Suggestions and Strategies for the Text Encoding Initiative », Journal of the Text Encoding Initiative [Online], Issue 7 | November 2014, Online since 01 January 2014, connection on 21 April 2019. URL : http:// journals.openedition.org/jtei/949; DOI : 10.4000/jtei.949 
TEI CODING INITIATIVE
Journal of the Text Encoding Initiative

Issue 7 | 2014

Reaching out, Opting in

\section{Evaluating Digital Scholarship: Suggestions and}

Strategies for the Text Encoding Initiative

Sarah L. Pfannenschmidt and Tanya E. Clement

\section{revues.org}

Electronic version

URL: http://jtei.revues.org/949

ISSN: 2162-5603

Electronic reference

The text is a facsimile of the print edition. 


\title{
Evaluating Digital Scholarship: Suggestions and Strategies for the Text Encoding Initiative
}

\author{
Sarah L. Pfannenschmidt and Tanya E. Clement
}

\section{Introduction}

1 Application of computers to the study of the humanities is receiving more attention, yet digital humanities continues to work through a digital incunabula phase (Crane et al. 2006), particularly in terms of critical evaluation. The history of evaluating digital scholarship is long and complex, and multiple scholars have contributed important points to the discussion (Schreibman, Mandell, and Olsen 2011; Cohen and Troyano 2012). ${ }^{1}$ However, one continuing concern is the need to define and outline fair evaluation criteria that will both enable improvement to digital methods and provide teaching examples of what is possible to the wider community (Rockwell 2011). Many scholars have argued that digital materials by nature contribute unique ontological and epistemological perspectives (Purdy and Walker 2010; McGann 2001) and require different evaluation criteria that those used for the original medium (Mandell 2010; Curran 2010; Presner 2012). Yet too often reviewers are still asked to evaluate materials without specific criteria, or to use criteria that may not be appropriate to a particular work (Tanselle 2006). Scholarly organizations, including the Modern Language Association (MLA) and the American Historical Association, have identified this concern and have provided suggestions as to general guidelines for evaluating digital scholarship (Modern Language Association 2013b; Working Group on Evaluating Public History Scholarship, 2010). While this is a much-needed step, interpretation and implementation of evaluation guidelines remains largely at the discretion of individual institutions. The choice of which evaluative standards to apply also depends on the context of the review (for a journal article or for tenure and promotion, for example) as well as the nature of the work (is it a digital scholarly edition or is it a tool?) being assessed. Another concern 
in evaluation is the degree of expertise the reviewers should have in both the technology and the subject area that covers the material under consideration.

2 The eclectic nature of digital scholarship poses challenges to the traditional method of finding one or two experts to take on review. The difficulty is partially due to the issue of determining what aspect of the scholarship is under review. A successful evaluation must be clear on what is being evaluated and why. The evaluation of digital tools in a larger project is a case in point. How should evaluators assess digital tools used in the production of scholarship: on the basis of a tool's usability, its theoretical framework, its underlying code, all of these things, or something else entirely (Anderson and McPherson 2011)? Text encoding is another example of this tension, because it reflects the process and methodology of editing, but may be more or less prominently featured in digital scholarship. It can therefore be unclear what aspect of the text encoding should be assessed (if at all) and who is qualified to evaluate it. Additionally, digital scholarship is, by necessity, collaborative and interdisciplinary. Determining the weight of the different aspects of a digital scholarly project is not an easy feat, since collaboration makes it difficult to distinguish the individual contributions within a group (Burgess and Hamming 2011) as well as the hierarchy of value attributed to team members. Yet no one person can be an expert in every method, field, and medium: seemingly, collaborative work requires collaborative review. Who then should contribute to a review, and what weight does their criteria carry? What happens when digital work challenges theoretical and technical boundaries in innovative ways, and how should reviewers note this innovation? Yet again, the concern lies in determining what to look for when judging a scholarly project's success or failure. After all, contributions to community may be in its failure to achieve certain goals rather than to meet them (Flanders 2009; Unsworth 1997). Evaluators of digital scholarship not only require clear guidelines, but must also have criteria flexible enough to allow them to assess the "success of failure," which challenges traditional definitions of scholarly value.

This paper presents select findings from our study of the TEI community's perspective on evaluating digital scholarship using the TEI Guidelines and the role that the organization should take in the review process. The focus for this study developed from the principal researcher's interest in the creation and evaluation of digital scholarly editions as well as Tanya Clement's interest, as the past reviews editor, in how the Journal of the Text Encoding Initiative (hereafter JTEI) might participate in the evaluation of digital scholarship. We used a very general definition of scholarship in this study since the burden of proving scholarliness is difficult and subjective. In general, we allowed participants to define scholarship according to their own understanding of the term. The project's specific focus on the TEI is due to the wide use of the TEI Guidelines. The National Endowment for the Humanities has recommended the TEI Guidelines as the accepted standard for encoding texts in digital scholarship. The evolution of the Guidelines into their fifth permutation also demonstrates longstanding interest in the TEI tag set and its applications (Text Encoding Initiative 2013b). The TEI Guidelines represent both a best practices standard as well as a theoretical approach to the markup of text (Cummings 2007; Renear 2004; Sperberg-McQueen, 1994), and thus make it particularly interesting to consider as both a method and a philosophy of encoding. The breadth and depth of the TEI community also attracted our attention. The TEI Consortium (hereafter TEI-C) is international, and TEI members come from various humanities disciplines with different experience levels in the application of the TEI tag set. Formal membership in the TEI organization requires 
financial support and gives voting benefits. Membership in the organization, however, is not required to use the TEI tag set, to join a special interest group, or to become an expert user in its application. Because the organization has a strong emphasis on promoting the tag set and teaching others to use it, there are many more users of the TEI than are formally recognized as members.

\section{Methods}

4 The study's target population consisted of people with experience in the creation and production of digital scholarship that incorporated TEI encoding. Twenty people were interviewed for the study. Nine of these interviews were conducted in person; the remaining interviews were conducted remotely. We were particularly interested in speaking with TEI users and did not require a specific competence level with the TEI Guidelines to participate. Participants were not required to be members of the Consortium and came from a variety of academic institutions. However, $50 \%$ of those interviewed have at some point held an official position in the TEI Consortium. Interview participants were recruited from the 2012 TEI Conference attendance list; from the email lists of the Humanist Discussion Group, the Digital Medievalist, and the TEI; and by personal invitation from the principal researcher's faculty advisor, Tanya Clement. Participants who expressed interest in being interviewed but were unable to do so in person were contacted to arrange for remote interviews via Skype.

5 Ten of the twenty participants were in tenure-track positions at research and teaching institutions across North America and Europe. Of these participants, at least five were tenured professors, and at the time of the interview a sixth was undergoing tenure review. The remaining ten participants held positions as independent scholars, librarians, and designated digital humanities staff. Interestingly, several of these participants described their work in terms that has been associated with the "alt-ac" label, though none of them used this term to describe themselves (Nowviskie 2010). All of the participants had experience in the creation of at least one scholarly digital project, especially editions of source texts. Most of the participants use or have used the TEI Guidelines and have positive opinions about its use as a standard for text encoding. Only $5 \%$ of the participants openly indicated that they did not view the TEI Guidelines as a useful community standard for text encoding.

6 Participants were asked to share their views on a series of topics centring on the evaluation of digital scholarship. Interviewees were allowed to opt out of any questions and also to determine the length of the interview. Individual interviews lasted from 10 to 75 minutes, and were conducted between November 9, 2012, and March 8, 2013. The principal researcher requested participants' permission to record the interview session in order to facilitate accuracy in the data and to maintain a conversational style. A document of consent was provided in person or electronically to participants, and consent was given to record the interview, with two exceptions. Notes were taken by hand during these two interviews. There were 10.5 hours of total recorded interview time. Recorded interviews were uploaded in mp3 format to a private computer and transcribed into text files. Transcribed files totalled 151 pages and were coded and scrubbed of personal or identifying information in order to ensure the anonymity of the participants. Additionally, each file received an alphabetical designation as the file name. 
Data were extracted and compiled by topic. Audio files were deleted following a final review of the transcripts.

\section{Results and Discussion}

7 We asked participants to consider the role of the TEI as an organization in the context of the evaluation of digital scholarship. In particular, we sought to discover whether participants felt that the organization could provide any contributions to the creation of evaluation criteria. The responses were strongly divided and revolved around two points: (1) what participants understood to be the organization's primary role and function, and (2) the perceived purposes and goals of the evaluation process. The biggest problem participants identified with evaluating text encoding was the same one facing the general digital scholarly community as a whole: namely, trying to define exactly what an evaluation would assess and why.

\subsection{Factors Complicating the TEI-C's Involvement in an Evaluative Context}

8 Some participants were not in favour of the TEI having a role in the evaluation of digital scholarship, stating that the TEI's involvement in assessment would negatively affect the organization's ability to carry out its core mission. In particular, there was concern about whether or not evaluation would interfere with the organization's stated docket of activities and current structure. This concern was especially pronounced in the areas of funding when participants considered the division of resources. One participant felt that the funding for the organization's current activities would make it difficult to implement evaluations:

If they wanted to introduce a process of ... assessment [that] will mean diversion of funding from other activities that they're doing ... to do it right and to do it fairly. I don't think it can be done on the backs of volunteers within the TEI, or it won't be fair enough to actually do what people are going to expect it to do, which is stand in for tenure and promotion cases ... and that means that they're probably going to have to do some form of cost-recovery ... if they're not going to divert resources and if you want to have it done properly.

(Participant 0)

Participant $\mathrm{O}$ suggested that funding is a practical consideration for the TEI-C should it request or expect this kind of participation from its members and user community. As a non-profit organization, the TEI-C would have to divert funds from its primary function to "collectively develop and maintain a standard for the representation of texts in digital form" (Text Encoding Initiative 2013a). The TEI-C would also have to consider whether it could justify the additional costs and time that would be required to do evaluations, and whether there is enough interest among TEI users and the general digital community to justify these costs. Thus, the TEI-C's decision to take on an evaluative role might require dedicated revenue streams for this purpose that would not tax the organization's current resources.

Clearly, the concern over resources was fundamentally related to how participants understood the TEI-C's function as an organization. One participant made the following comment: 
What is the TEI, as it were? You know, it's a not-for-profit organization, there is a council, there is a technical board, ${ }^{2}$ but there are many, many people in the community who are interested in TEI, use TEI encoding, but are they the TEI. . . ? So it's kind of saying 'Well, the MLA should be in charge of something, [or] the MLA should participate,' but who is the MLA? A body of people who work in New York and a lot of members.

(Participant N)

11 Like the TEI, the MLA is an organization designed to allow members to "share their scholarly findings and teaching experiences with colleagues and to discuss trends in the academy" (Modern Languages Association 2013a). Both organizations host an annual convention, publish relevant materials, and maintain a style guide. The TEI-C's equivalent of the latter is the TEI tag set for text encoding. Like the MLA, the TEI-C makes suggestions for practitioners, but they cannot enforce them. Instead, they combine the experience of members and users to provide assistance to others. As noted by Participant $\mathrm{N}$, however, the TEI-C and the MLA are not comprised of people who are all part of the same scholarly discipline; the MLA covers different specialties within the study of language and literature, while the TEI-C welcomes scholars from all fields. Instead, these communities would be more appropriately defined as a loose association of users bound by a common interest. What the TEI-C is not, however, is a judicial body in the practice of text encoding and markup, even within its own community.

Participants recognized that by assigning an evaluative role to any aspect of the TEI-C's activities, they would potentially promote narrowness in the application of the TEI tags and, indeed, in the wider practice of text markup. Textual editing is by nature both flexible and formative, and two different editorial methodologies may produce work that demonstrates equally interesting perspectives. Consequently, it is not always possible to determine what is "better" about one choice over another. The TEI Guidelines attempt to accommodate many of the variations that can occur in editing texts. Therefore, there is no absolutely correct way to encode a text beyond what will validate for a given set of parameters set up in the ODD file or schema and rendered by an XSLT transformation or a similar process. Participant D questioned the need to evaluate the application of tags at all: "[one specific vision of the TEI tags is] not a generalized tool that somebody else could use unless they were doing exactly the same thing. So in that case, there's no real point in assessing unless you're wanting to assess me [and] how good I was at that job." Based on Participant D's understanding, a specific use of the TEI tags may not be generalizable. Evaluation of a given use of the TEI tags may focus on the individual editor and not the more important aspect of the review: the product itself. Any attempt to evaluate individual preferences shy of an encoded document that does not render would be politically and practically difficult. The TEI tags are deliberately flexible to allow for a wide range of applications, and some participants did not want to limit this range in any way.

13 Practitioners who know the TEI standards best may also have preferred ways of using and interpreting the tags. These preferences are partially subjective, and at present, no single view of the TEI tags is necessarily "right" in every situation. Some participants added that, should the TEI-C become involved in the evaluation process, one interpretation of the TEI tag set might be unfairly promoted: "if you focus the work of evaluation in a single place, you run the risk of having people essentially beg the question of what's valid TEI by just ... pleading essentially their own version by their own interpretation" [Participant Q]. The participant highlights the concern that giving one person or select 
group of people the authority to decide what kind of TEI tags are "right" could privilege one interpretation of the TEI standards over another equally valid interpretation. In order to avoid unnecessary rigidity, the TEI-C would therefore need to be very clear in determining what exactly was being evaluated and what weight this carried for the assessment of the work as a whole. One participant succinctly noted that such an approach was in direct contrast with the original purpose of the organization's initiative, which was "to be a community standard, a 'this is the way we all agreed to do this stuff' standard ... not a 'from on high thou shalt' standard" [Participant G]. These responses emphasize the difficulty in evaluating the use of the TEI tag set. Participants were largely unclear about what aspects of the text encoding could be evaluated. Possible criteria mentioned by participants included the understanding of the individual editor of the TEI standards, their demonstrated use of those standards, and the application of the TEI tags to further a specific editorial theory of the text.

Participants also connected the concern over internal orthodoxy in the TEI to a larger issue of a text encoding bias in evaluation. In particular, some participants felt that the TEI-C's involvement in evaluation would begin to limit what could be considered legitimate text-encoding practices. In the words of one participant, if the evaluation of text encoding was undertaken by the TEI-C, then it was possible that the organization would "have a sort of monopoly" on how text encoding would be evaluated by the digital scholarly community at large [Participant S]. The TEI tags are not the only way to encode text, nor do practitioners claim that using TEI tags is the best choice in all cases (Lavagnino 2006). Any organization may be seen as having a clear stake in judging its own materials. Participant $R$ noted that while "there are people who are practitioners, familiar with various kinds of guidelines [they] also aren't making those guidelines at the same time." The difficulty for participants appears to be in trying to determine how the TEI-C could judge itself fairly without potential bias. In other words, who watches the evaluators?

There was also a mention of the concomitant danger of valuing text encoding over other facets of the scholarly product. Participant $\mathrm{P}$ cautioned that there is typically more involved in a digital work than simply text encoding, and evaluation should take this into account:

Ideally the TEI [tagset] is just one component of a successful digital project. That there are other things layered on top of that, you know, topic modeling, information visualizations, GIS stuff and so on, so having the TEI as the home for this is putting too much attention on one aspect of a project when you have all these other technologies involved that may be just as important as the TEI.

Digital projects, particularly those that require scholarly digital editing, frequently use text encoding and may choose the TEI tags to accomplish this encoding. However, the TEI tags are not the only "digital" aspect of a digital scholarly endeavour, and they may not even be the most important or interesting component to assess:

It's not $100 \%$ clear to me that you can't do good work that isn't TEI based. And so I would be a little bit nervous that you don't end up as an orthodoxy agency, and especially given that ... the really really interesting stuff right now seems to be geospatial and semantic, and ... also interoperability, so stuff with JSON and things like that, and I think it might be wrong to just choose markup [as an evaluation metric].

(Participant Q) 

factors, especially if the text encoding is not the most interesting or innovative aspect of the work? The use of the TEI tags is not inherently indicative of a rigorous scholarly methodology. Therefore, some participants argued that the quality of the markup should not be considered a reflection of the material's overall scholarly quality.

Some participants also believed that the TEI-C would not be able to provide evaluations that would carry weight in specific academic disciplines. As one participant explained, "Assessment is never neutral. It usually has some form of practice or method or technique, and it has stakeholders. It's done by somebody, to somebody, for somebody" [Participant O]. It would therefore be necessary to identify the purpose of an evaluation in order to determine if the TEI-C was the appropriate group to participate. For some participants, this was precisely the reason why the TEI-C should not be an evaluative body: the organization was not designed as a peer-review system, and it does not carry the same academic weight among other peer-reviewed scholarship. The perceived limitation in the TEI's evaluative focus means that evaluations by the TEI-C would be of limited use to persons seeking tenure or other forms of scholarly advancement in traditional departments.

Participants reasoned that other groups, specifically NINES and its sister organizations, would be more appropriate forums to evaluate digital scholarship. These groups are more readily identified as scholarly peer-review bodies because they were designed to review scholarship. According to its website, NINES identifies as a "scholarly organization" with three primary goals: (1) "to serve as a peer-reviewing body for digital work" in a specific time period (1770-1920) and in a specific area (British and American), (2) "to support scholars' priorities and best practices in the creation of digital research materials," and (3) "to develop software tools" to promote these activities. ${ }^{3}$ The key point is that NINES calls itself a scholarly organization and is comprised of scholars working in a specific field defined by spatial and temporal criteria who use or create digital tools to facilitate their studies. Participants believed that a review by NINES was more likely to be accepted by academic committees as evidence of scholarly value because the members of the editorial boards, as well as the scholars solicited for reviews, are recognized experts in the field that they are reviewing. In contrast, Participant $P$ explained that the TEI-C is not a peerreview system, but rather a community interested in a specific topic, that of text encoding: "There are different functions for different types of bodies ... the TEI is really good at maintaining the standard and pushing that out to users and so on, and the reviewing aspects are better handled by groups like NINES." Another participant confirmed this perspective:

TEI is not, or cannot, I should say, [provide] field-specific scholarly review. Because the TEI is fantastic ... [but] if TEI were to give their stamp of approval to my project, and if I were to submit it to a committee for promotion, they wouldn't know what to make of it, because they're not in the field. I mean, it's in the field of digital studies ... but evaluating scholarly relevance or pedagogical relevance is really a completely different story. So I would hope that these field-specific or era-specific literary humanities oriented review sites would actually solve [the reviewing] problem.

(Participant S)

While many scholars are involved in the TEI community, the TEI-C's declared goals and activities are centered on text encoding, not necessarily on singular areas of scholarship. 
Consequently, some participants in traditional academic jobs saw the TEI-C's participation in scholarly reviewing as only partially beneficial.

21 For some participants, this perspective on the TEI-C's capacity to review digital scholarship highlighted the divide between traditional and non-traditional scholars. Participant $\mathrm{P}$ identified this problem in terms of the discrepancy between the role of the TEI-C and the role of peer-review groups like NINES in offering an evaluation of digital scholarship:

... There are many people who are excellent, really productive members of the TEI community and on the Board and Council who aren't traditional, who aren't professors. And I don't like to categorize people in those ways, but when it comes to something like tenure and promotion, you're going to have people who will put people into those sorts of categories. I think you want the reviewing done by bodies that are made up predominantly of people in tenure or tenure-track positions to get over those biases. If you could have three members from the TEI council who were doing a review of a project for someone's tenure, and they could be computer programmer, and a librarian, and a IT support person, all great scholars and TEI experts, but that might not be convincing to a more traditional person on a tenure and promotion committee, who wants those reviewers to be more traditional scholars. And that's the problem, I think, and I think that different people in digital humanities are working to legitimize the roles and qualifications of these altacademic positions. But it's still a problem for people going up for tenure and promotion.

This statement has hit on many of the concerns of the digital community: its legitimacy, its relationship to the traditional academy, and the place of non-tenure-track scholars. For this study, the most important point identified by Participant $\mathrm{P}$ is that more value is still inherently attached to a review from a peer-review group comprised of traditional academics than one that has been done by alternative academics or persons working in fields other than the project-specific one. Again, the TEI-C was not designed to be a peerreview body for an academic field. Therefore, these participants believed that it would be difficult for the TEI-C to perform evaluations without further work being done, as Participant P advocates, to "legitimize the roles" or otherwise establish that its members were able to demonstrate subject knowledge in addition to text-encoding expertise.

\subsection{Factors Favouring the TEI-C's Involvement in an Evaluative Context}

Despite these concerns, some participants maintained that there were several important reasons to have the TEI-C involved in evaluation. Indeed, some participants who had originally expressed objections to the possibility of the TEI community's involvement also noted that the idea warranted further consideration. The main points given in favour of evaluations by the TEI-C were as follows: (1) that the TEI tags could be considered part of the editorial methodology that contributes to the scholarship of a project, and are therefore, by necessity, evaluable; (2) that the organization has a declared responsibility as a "resource to scholars" to provide assistance if requested in this area; and (3) that by making the effort to review such projects, the organization would provide an environment for further dialogue on both the use and future directions of the tag set, as well as the development of evaluation criteria.

24 Participants who were in favour of having the TEI-C involved in evaluation of digital scholarship connected the use of tags with a project's editorial methodology. Editorial 
decisions about how to encode the text affect the scholarly quality of the project. The connection to the overall vision of the project led participants to reason that the text encoding should be considered part of the project's scholarship and evaluated as such:

... the act of encoding itself is an act of scholarship. Right? You wind up dealing closely with the text and making editorial decisions that not only in and of itself is sort of good for your health, but is adding to the world of scholarship, producing new knowledge in a sense. You are providing your own analysis, and your analysis, while maybe not described in prose the way it would be in a monograph or a journal, becomes implicit in what you do ... it itself is a sort of work ...[and] this is what you would want to be evaluating.

(Participant M)

Participant $M$ noted that there is a correlation between editing, markup, and scholarship, or the "theory of digital text" (Fiormonte, Martiradonna, and Schmidt 2010). The theory and its application to a text, as well as the consistency of that application, is reflected in the product. The text-encoding and tagging choices are therefore related to the entire editorial methodology of a scholarly work:

I think that [where] tagging and text, the marking of a text, fit between editorial practice and writing an essay, or a book, comes down to the level of granularity, I think, that you tag. Because in tagging, that's one of the main questions ... [so] the decisions that you have to do as to how much granularity, to deal with the text, is certainly, at least as scholarly as trying to figure out what kind of edition to write. And so it's in that process of deciding the edition, in the process of justifying an edition, in the process of figuring out the details that will go into the textual apparatus in an edition, which are the most scholarly parts of an actual edition text.

\section{(Participant S)}

According to this response, evaluating text encoding depends on the depth of tagging (that is, the "granularity") that an editor uses to approach the material. When an editor marks up the text in a detailed, methodical way, the text encoding becomes both an implicit and explicit part of their theory of the text. Participant responses suggest that the theory of the text, at the very least, is scholarship. The problem therefore is not whether text encoding can be scholarship, but rather how the creators of the project make such an argument explicit to reviewers.

Some participants generally felt that if a project utilized TEI tags, the text-encoding choices should be considered in any fair and holistic evaluation. One participant compared the text encoding of a digital project with the editorial methods of a print edition:

I think if you are evaluating the scholarly value of the digital project whose underlying data is in TEI, you really do need to look at that TEI. In the same way as if you were evaluating a letterpress edition, you would certainly be looking very carefully at the editorial methods section. You'd be looking at the transcription principles ... to see that the conventions were applied consistently ... if you weren't using that as a reviewer ... you'd be leaving out half of what makes it a scholarly edition. And I think that's true of anybody who is claiming that they are making use of TEI to code for archival purposes. I mean, if it's very simple content and you're really just coding paragraphs and lines that might not apply. But if you're doing anything more sophisticated to capture things like textual variants and manuscript witnesses, or semantic or linguistic features of the text, then you ... should be getting credit for the work you've done, and also if it hasn't been done well, then that should be part of the evaluation.

(Participant L) 
Like Participant S's statement about the granularity of encoding, Participant L asserts that there is room for evaluation of text encoding when it comes to "capturing" unique textual information. The comparison with traditional editorial print methods highlights the problematic position of editorial theory and practice and the value afforded these activities in academia. Critical editing has been unfairly treated as an inferior type of scholarship (Greetham 1997), and the scholarly legitimacy afforded to the activity of editing and producing critical texts depends on the purpose of the evaluation. If participants promoted text encoding as scholarship by virtue of its role in editorial theory, then they were more likely to say that the text encoding should also be evaluated for scholarly credit and that the TEI-C was the appropriate group to do this.

Several participants argued that the TEI-C should be involved in project assessment in the capacity of advocate. Those participants who identified the TEI-C as a potential evaluative body felt that the organization as a whole could help scholars both improve their projects and legitimize their scholarship to the wider community. Not surprisingly, support for the place of the TEI-C in legitimizing scholarship was predominantly expressed by participants who were less experienced with the TEI tags, whose work fell outside large and well-supported areas of scholarship (such as American or English literature), who were junior tenure-track scholars, or who were in alternative academic posts. In the words of one participant, there needs to be "a lot more work on the part of the scholar ... to educate people about digital humanities scholarship," especially with regards to the expectations and possibilities of digital tools and methods [Participant P]. In other words, scholars need assistance to plead their case, and those who need such assistance would like the TEI-C to provide it. As Participant O stated, "wherever you stand on whether or not there's scholarship [in a project], it is still the case that we have people who are arguing that it is, and that therefore the TEI should provide guidelines for [evaluating] this." In other words, the TEI-C could help to provide standards for evaluating textencoded materials that others could use to perform fair reviews. These reviews would be useful in reaching out not only to the non-digital community, many of whom still do not recognize text encoding and other digital methods as legitimate scholarship, but also to other evaluative bodies. For example, Participant $\mathrm{H}$ said that "If [the funding bodies] knew the TEI and the quality of the encoding that is possible in this way ... in order to have an idea of the real amount of work [they would] better understand our achievements." Participant $\mathrm{R}$ agreed with this perspective and explained that "to make digital scholarship evaluable, part of what you need to do is talk about it a lot, explain it a lot, and in a sense, publicize it." These scholars drew a connection between the need to legitimize digital scholarship and the advocacy role of the TEI-C.

The suggested form for the TEI-C's advocacy was as a formative consultant. Although the TEI-C already does a significant amount of outreach, providing formative reviews was seen as a resource for those with beginning to intermediate knowledge of the TEI tags. Several of the participants who are junior scholars said that the complicated nature of the TEI tags and the length of time required to become an expert in using them made it prohibitive for them to use the tag set with greater proficiency: "I feel that for someone like me who can't practice TEI all the time because I have other scholarly demands, I think that that becomes hard [to improve my use of the TEI tags]" [Participant R]. As expressed here, an insufficient knowledge of the Guidelines limits the scholar's ability to use them to best reflect their editorial methodology. In turn, they need the formative assessment to help them with later evaluations: "I think that ... I would want someone 
who was looking at the TEI to understand what the intentions were in order to kind of judge the scholarly aspect of it" [Participant R]. Participant $\mathrm{R}$ wanted a formative assessment to improve their ability to correctly apply the tag set at a more sophisticated level, which in turn would make their argument for scholarship more legitimate in a later evaluation. As Participant M said, the "primary place [of the TEI-C] is to serve the needs of scholars who are producing digital editions." Scholars who want to demonstrate that their text encoding reflects scholarship require a mechanism by which they can make their argument legitimate to evaluators. Participant $\mathrm{T}$ explained that the value of the TEIC stems from its ability to "expose ... [and] publicize the process of editing" to others; that is, to demonstrate how editorial theory and methodology incorporate the TEI tag set to produce scholarship.

\subsection{Forms of Participation: Potential Avenues for the TEI-C's Involvement in Evaluation}

31 Regardless of how participants felt about the place of the TEI-C in the review process, all participants were asked to consider what form such participation might take. In general, the majority of participants felt that the organization should provide a reference document as an evaluation resource. As Participant I explained, "We should be proactive in suggesting guidelines for evaluation because so many tenure committees and evaluation committees don't know where to start." Users of the TEI tag set cover all levels of proficiency; some are experts. In contrast, many evaluative bodies do not have knowledge of text encoding (of any form, not just the TEI tag set) or know how to evaluate it. As such, the documents would assist reviewers by promoting a better understanding of what an assessment of text encoding might look like among the more traditional and less technically savvy review bodies. Participant $\mathrm{S}$ explained that there is a "need for actual expert reviewers out there, or at least some sort of firewall that you can submit something to and have it get a stamp of approval, that not only does meet best practices for a digital edition which is a technical evaluation, but it also has some scholarly merit, or at least utility for the field." Another participant expressed a similar opinion, going so far as to suggest that there should be additional documentation to assist in the creation of evaluation criteria that would facilitate such reviews:

I think the TEI would be better off first of all maybe commissioning guidelines for assessment. So saying, 'this is how we would assess it if you were a chair, or someone on a tenure committee, or whatever it is, this is ... what we recommend you do as part of an assessment.' Sort of describe commission and the creation of a best-practices document. And then share that best practices document with the community.

(Participant 0)

Other participants suggested that the TEI-C provide a list of the names of people who could assist with early and intermediate assessments. The TEI-C would, in this sense, not be taking the place of the peer-review body, but particular members could answer questions with respect to the editorial decisions and use of the TEI tags in a given situation. As one participant explained, "If ... you have a project and you want to make sure that your project is set up, the TEI[-C] is ... a mechanism by which experts are put in touch with projects that need advice" [Participant Q]. Such formative assessment and consulting may benefit both the TEI-C and the material under review. Reviewing digital scholarship early in the development and planning process as well as in res medias is 
potentially more cost effective. Also, receiving an outside perspective may help scholars to avoid common mistakes in their infrastructure and editorial decisions:

It should become a best practice to weave into [the project budget] some funding to bring someone up to consult, to get some sort of outside view, and so that's a form of assessment that the TEI[-C] could help with.... the TEI might want to provide recommendations or ideas about this type of formative assessment for projects. Because these projects-earlier in the project, they soak up money. A good outside consultant can save you money ...

(Participant 0)

33 Not only would a consultation potentially save money, but it would also allow the TEI-C to help promote best practices and innovation in the use of text encoding and its intersection with other tools. One of the criteria given for evaluation was whether the scholarship contributed additional knowledge that would lead to improvement of the tools that it used. Thus, these activities may also help the TEI-C identify future improvements as more people continue to use, learn, teach, and refine the TEI Guidelines through the evaluation of digital scholarship. Consultation and review could also benefit project leaders in that they would be forced to consider their methodology and begin documenting their editorial decisions earlier. As demonstrated in the previous discussion, such assistance was exactly what several of the junior scholars and participants outside of large fields of scholarship had stated as a primary reason why they wanted the TEI-C to be involved in the evaluation process.

Several participants suggested that the JTEI could provide an appropriate forum to highlight reviews of the TEI tag set and its use in digital scholarship. The online availability and lack of access restriction was particularly appealing for participants. Using the JTEI as a forum for review would also meet the stated goals of the journal to "disseminate as widely as possible information about the TEI and its applications to scholarship" and to provide "a forum for ... discussion of ... the role of technological standards in the digital humanities." ${ }^{4}$ Currently there is no dedicated project review section. If the JTEI was to include a section that provided a forum for discussing scholarship evaluation, it could publish and commission reviews of completed and ongoing work. As one participant noted, the JTEI could "Make the review process itself useful to people ... that's where I would recommend the TEI Journal. It should get into reviewing. If they had a reviews column, then people who did [the reviews] could rewrite their reviews and submit them and get it published, just like a book review" [Participant O]. The JTEI could decide whether or not to provide short reviews and links, or "more critical pieces that also deal with some other factors ... like new uses of P5 ... [to give] people the space to be more thoughtful" [Participant N]. By providing reviews of digital scholarship, the JTEI would function as a kind of "vetting" space, a place that will not only "get people up to speed from the initial understanding of the TEI" but also show the more experienced members of discipline-based communities how to expand the possibilities of the use of TEI tags in scholarly work [Participant R]. Certainly, some participants saw the JTEI as the ideal platform for disseminating evaluations primarily because the journal functions more like a traditional print-based mechanism.

\section{Future Directions}

Despite the fact that participant perspectives on the TEI community's involvement in evaluating digital scholarship varied widely, there are a number of important 
conclusions. The first is that most of the participants indicated that a part (in this case, the evaluation of text encoding) could not serve as an evaluation of the whole. Second, participants by-and-large believe that the TEI-C is at present not equipped to evaluate digital scholarship in the same way as NINES and similar groups because its infrastructure is not designed as a field-specific peer-review body. Third, some participants noted that the TEI-C would critique scholarly materials according to its own approach to encoding, but there is no one way to apply the TEI tag set. Thus, there is concern that the TEI-C would be prone to bias if the organization attempted to review the philosophy and execution of encoded scholarly materials.

However, there were also a number of compelling reasons given for why the TEI-C and the user community are strategically placed to make valuable contributions to the evaluation of text encoded digital scholarship. It would be a considerable asset for the scholarly community if the TEI-C supplemented the activities of other evaluative groups and provided materials and examples for the assessment of text encoding. In many cases, these groups may not have persons experienced in the application of the TEI tag set, and thus would benefit from input from experienced members of the TEI user community. Ideally, the next step would be to commission case studies to test and demonstrate how these collaborations would work in practice. The intent is that these case studies would foster additional dialogue within the user community and among dedicated peer-review groups such as NINES on the ways in which the TEI-C might best contribute. Another area where the TEI-C may be able to benefit the community is in providing evaluative assistance to scholars at crucial points in project development. Such assistance might help resolve expensive and time-intensive problems earlier in the development process. Again, case studies would be a beneficial avenue to explore further in this regard. Other evaluative bodies may also benefit from this aspect of review because there will be a record of the suggestions given on a project during the consultation, thus providing a context for the final form that the project takes. Finally, the results of this study suggest that exploring avenues of review within the context of the JTEI would be a promising next step. We envision something along the lines of a dedicated project reviews section, though the exact form that this would take is still under consideration. Although there are no easy answers in establishing criteria to evaluate digital scholarship, participant responses suggest that assessment of a text encoding philosophy would still be most appropriately left to those who have experience in the development and application of tag sets. With regards to the TEI, scholars that have developed and use the Guidelines are needed to provide evaluative assistance to others, and may in turn add to the pedagogical resources requested for use by the larger community.

\section{BIBLIOGRAPHY}

Anderson, Steve, and Tara McPherson. 2011. "Engaging Digital Scholarship: Thoughts on Evaluating Multimedia Scholarship.” Profession 2011: 136-51. doi:10.1632/prof.2011.2011.1.136. 
Burgess, Helen J., and Jeanne Hamming. 2011. "New Media in the Academy: Labor and the Production of Knowledge in Scholarly Multimedia." Digital Humanities Quarterly 5(3). http:// www.digitalhumanities.org/dhq/vol/5/3/000102/000102.html.

Cohen, Daniel J., and Joan Fragaszy Troyano. 2012. “Closing the Evaluation Gap.” Journal of Digital Humanities 1(4): i-ii. http://journalofdigitalhumanities.org/1-4/.

Crane, Gregory, David Bamman, Lisa Cerrato, Alison Jones, David Mimno, Adrian Packel, David Sculley, and Gabriel Weaver. 2006. "Beyond Digital Incunabula: Modeling the Next Generation of Digital Libraries." Research and Advanced Technology for Digital Libraries (ECDL 2006), Lecture Notes in Computer Science 4172, edited by Julio Gonzalo, Costantino Thanos, M. Felisa Verdejo, and Rafael C. Carrasco (Berlin and Heidelberg: Springer Verlag), 353-66. doi:10.1007/11863878_30.

Cummings, James. 2007. “The Text Encoding Initiative and the Study of Literature.” In A Companion to Digital Literary Studies, edited by Ray Siemens and Susan Schreibman, 451-76. Oxford: Blackwell Publishing.

Curran, Stuart. 2010. "Different Demands, Different Priorities: Electronic and Print Editions.” Literature Compass 7(2): 82-88. doi:10.1111/j.1741-4113.2009.00679.x.

Flanders, Julia. 2009. “The Productive Unease of 21st-Century Digital Scholarship.” Digital Humanities Quarterly 3(3). http://www.digitalhumanities.org/dhq/vol/3/3/000055/000055.html.

Fiormonte, Domenico, Valentina Martiradonna, and Desmond Schmidt. 2010. "Digital Encoding as a Hermeneutic and Semiotic Act: The Case of Valerio Magrelli." Digital Humanities Quarterly 4(1). http://www.digitalhumanities.org/dhq/vol/4/1/000082/000082.html.

Greetham, David C. 1997. "The Resistance to Philology." In The Margins of the Text, edited by D. C. Greetham, 9-24. Ann Arbor, Michigan: University of Michigan Press.

Lavagnino, John. 2006. “When Not to Use TEI.” In Electronic Textual Editing, edited by Lou Burnard, Katherine O'Brien O'Keeffe, and John Unsworth, 334-48. New York: Modern Language Association of America.

Mandell, Laura. 2010. "Special Issue: 'Scholarly Editing in the Twenty-First Century-'A Conclusion." Literature Compass 7(2): 120-33. doi:10.1111/j.1741-4113.2009.00684.x.

McGann, Jerome. 2001. Radiant Textuality: Literature after the World Wide Web. New York: Palgrave.

Modern Language Association. 2013a. “About the MLA.” Last modified June 5, 2012. http:// www.mla.org/about.

---. 2013b. “Guidelines for Evaluating Work in Digital Humanities and Digital Media." Last modified December 20, 2013. https://www.mla.org/guidelines_evaluation_digital.

Nowviskie, Bethany. 2010. “\#Alt-Ac: Alternate Academic Careers for Humanities Scholars.” Accessed March 23, 2013. http://nowviskie.org/2010/alt-ac/.

Presner, Todd. 2012. "How to Evaluate Digital Scholarship." Journal of Digital Humanities 1(4): 3639. http://journalofdigitalhumanities.org/1-4/how-to-evaluate-digital-scholarship-by-toddpresner/.

Purdy, James P., and Joyce R. Walker. 2010. "Valuing Digital Scholarship: Exploring the Changing Realities of Intellectual Work.” Profession 2010: 177-95. doi:10.1632/prof.2010.2010.1.177.

Renear, Alan. 2004. “Text Encoding." In A Companion to Digital Humanities, edited by Susan Schreibman, Ray Siemens, and John Unsworth, 218-39. Oxford: Blackwell Publishing.

Rockwell, Geoffrey. 2011. “On the Evaluation of Digital Media as Scholarship." Profession 2011: 152-68. doi:10.1632/prof.2011.2011.1.152. 
Schreibman, Susan, Laura Mandell, and Stephen Olsen. 2011. "Evaluating Digital Scholarship: Introduction.” Profession 2011: 123-35. doi:10.1632/prof.2011.2011.1.123.

Sperberg-McQueen, C. M. 1994. “Textual Criticism and the Text Encoding Initiative.” Paper presented at the annual Convention of the Modern Language Association, San Diego, California, December. http://www.tei-c.org/Vault/XX/mla94.html.

Tanselle, G. Thomas. 2006. Foreword to Electronic Textual Editing, edited by Lou Burnard, Katherine O'Brien O'Keeffe, and John Unsworth, 1-6. New York: Modern Language Association of America.

Text Encoding Initiative. 2013a. TEI: Text Encoding Initiative. Accessed March 17, 2013. http:// www.tei-c.org/index.xml.

-_-. 2013b. “Projects Using the TEI.” Accessed April 9, 2013. http://www.tei-c.org/Activities/ Projects/

Unsworth, John. 1997. “Documenting the Reinvention of Text: The Importance of Failure.” Journal of Electronic Publishing 3(2). doi: 10.3998/3336451.0003.201.

Working Group on Evaluating Public History Scholarship, 2010. “Tenure, Promotion, and the Publicly Engaged Academic Historian.” Journal of Digital Humanities 1(4): 98. http:// journalofdigitalhumanities.org/1-4/tenure-promotion-and-the-publicly-engaged-historian/.

\section{APPENDIXES}

\section{Appendix 1. Interview Questions}

1. Should the TEI-C have a role in the evaluation of digital scholarship? Please explain.

2. What form should contributions to the discussion of the evaluation of digital scholarship from the TEI-C take?

3. Is text encoding a scholarly activity? Why or why not?

4. When should a TEI tagged work be evaluated? What are the benefits of formative reviews?

5. How could we evaluate text encoding in digital scholarship? As a digital tool? As part of the larger editorial methodology?

6. Who would review a TEI tagged project and what criteria would they use?

\section{NOTES}

1. See also NINES (Networked Infrastructure for Nineteenth-Century Electronic Scholarship), "Evaluating Digital Scholarship: NINES/NEH Summer Institutes: 2011-2012," accessed December 29, 2012, http://institutes.nines.org/.

2. To be precise, it's the TEI Technical Council that guides the 'technical direction of the TEI Consortium.' The TEI Board supervises the TEI Consortium, 'provides strategic direction and fiscal oversight, organizes the TEI's main activities, and coordinates fundraising and member recruiting.' (

‘TEI: Organization,' http://www.tei-c.org/About/organization.xml 


\section{) .}

3. NINES (Networked Infrastructure for Nineteenth-Century Electronic Scholarship), "What is NINES?," accessed March 13, 2013, http://www.nines.org/about/.

4. Journal of the Text Encoding Initiative home page, accessed March 21, 2014, http:// journal.tei-c.org/journal/index.

\section{ABSTRACT}

As part of a larger pilot study on the evaluation of digital scholarship, we consider what role, if any, the TEI Consortium and user community might play in evaluating scholarship that utilize the TEI tag set. Our rationale for focusing on the role of the TEI Consortium in the discussion of evaluation is twofold. First, the TEI Guidelines represents an encoding standard for texts that is supported by a large community actively interested in the application and development of these standards. Second, feedback concerning evaluation criteria for digital scholarship has not been explicitly gathered from the TEI community and may provide additional understanding of the value, process, and assessment of text encoding. Determining what to evaluate and how to do so reveals the community's definitions of scholarship in general. The clarification and articulation of evaluation criteria, therefore, remains a high priority as digital scholarship continues to develop.

\section{INDEX}

Keywords: evaluation criteria, digital scholarship, pilot study, text encoding

\section{AUTHORS}

\section{SARAH L. PFANNENSCHMIDT}

Sarah L. Pfannenschmidt, M.St., M.A., is a 2013 graduate of the MSIS program at the University of Texas at Austin School of Information, where her focus was on rare books and digital scholarly editing. Her ongoing research includes editing medieval Welsh, Irish, and English texts and the creation and use of digital editions.

\section{TANYA E. CLEMENT}

Tanya Clement, Ph.D, is an assistant professor at the University of Texas at Austin School of Information. Her primary area of research centers on scholarly information infrastructure as it impacts academic research, research libraries, and the creation of research tools and resources in the digital humanities. 